\title{
Is there a relationship between zinc and the peculiar comorbidities of Down syndrome?
}

\author{
Corrado Romano, Rosa Pettinato, Letizia Ragusa*, Concetta Barone, Antonino Alberti \\ and Pinella Failla \\ Unità Operativa Autonoma di Pediatria and Unità Operativa Aggregata di Endocrinologia*, Oasi Institute (IRCCS), Troina (EN), Italy.
}

\begin{abstract}
Zinc plays a central role in the immune system and has been found to be significantly reduced in people with Down syndrome. The effectiveness of zinc supplementation in people with Down syndrome has been reported with discordant results. A comparison was made between a range of clinical and biochemical variables and zinc levels in 120 individuals with Down syndrome. Two groups of participants, one with normal zinc levels and the second with low zinc levels, were compared on the following measures: growth hormone secretion, $\lg A$ and $\lg G$ antigliadin antibodies, presence of coeliac disease, T3, T4, fT3, fT4, TSH, hypothyroidism, hyperthyroidism, CD4/CD8 ratio, total immunoglobulins $G$ and subclasses. No significant difference was found between the two groups, except for lgG4 which was, unexpectedly, significantly decreased in the group with normal zinc levels. In conclusion, an impairment of zinc blood level in individuals with Down syndrome does not necessarily impact on the organs and systems evaluated here.
\end{abstract}

Keywords - Down syndrome, zinc deficiency, growth hormone, hypothyroidism, coeliac disease, CD4/CD8 ratio, lgG4.

\section{Introduction}

The need of zinc for the growth and survival of animals has been known since 1934 (Todd, Elvejheim \& Hart, 1934), but its necessity in human beings was only shown thirty years later (Georges, 1963). Prasad (1991) published a review of the evidence supporting the existence of zinc deficiency as a disease in medicine. A range of clinical features has been observed in association with zinc deficiency. The mild type appears with minor impairments of the immune system, taste and smell, night blindness, memory deficiency and decreased spermatogenesis (Walsh, Sandstead, Prasad, Newberne \& Fraker, 1994; Zalewski, 1996). The severe type shows severe immune impairment, frequent infections, pustular-bullous dermatitis, diarrhoea, alopecia and mental disturbances (Walsh et al., 1994; Kay \& Tasman-Jones, 1975). Similar effects are found in animals with zinc deficiency (Walsh et al., 1994; Zalewski, 1996; Clegg, Keen \& Hurley, 1989). Acrodermatitis enteropatica is the prototype of a disease due to zinc deficiency. It is a rare genetic disease due to the decreased absorption of zinc which has an autosomal recessive mode of inheritance. Its clinical features are acral hyperpigmented skin lesions, bullous dermatitis, alopecia, lack of eyelashes and eyebrows, poor growth, pancreatic islet cell hyperplasia, lack of thymus, intermittent diarrhoea, lymphoid and splenic plasmocytosis, low zinc in blood and urine, and low alkaline phosphatase in the serum. The main functions of zinc can be inferred from the symptoms of zinc deficiency. Zinc plays a central role in the immune system and, consequently, in resistance to the infections. Severe zinc deficiency is associated with damage of epidermal cells (Aggett, 1989), which is seen in the skin lesions of acrodermatitis enteropatica (Hambidge, Walravens \& Neldner, 1977). Damage of gastrointestinal and respiratory mucosa (Walsh et al., 1994; Solomons, 1988), involvement of specific immune cells, such as polymorphonuclear cells (Weston, et al., 1977; Briggs et al., 1982; Singh, Failla \& Deuster, 1994), natural killer cells (Allen, Perri, McClain \& Kay, 1983; Salas \& Kirchner, 1987) and the complement cascade (Jepsen, Teisner \& Svehag, 1990) also occurs.

\section{Zinc and Down syndrome}

Bjorksten et al. (1980) reported low zinc serum levels in 12 people with Down syndrome, with impaired neutrophil chemotaxis and lymphocyte response to phytohemagglutinin. Two months after supplementation with zinc sulphate, zinc serum levels increased, neutrophil chemotaxis normalised in 11 out of 12 patients and the lymphocyte response to phytohemagglutinin improved. Tukiainen, Tuomisto, Westermarck and Kupiainen (1980) demonstrated that zinc causes a dose-dependent inhibition of 5-hydroxytryptamine uptake in vitro, but zinc supplementation does not lead to significant effects in vivo. Zinc, copper and selenium are essential microelements of the enzymes superoxide dismutase and glutathione peroxidase, whose activities have been reported to be increased in the erythrocytes of people 
with Down syndrome. In a study (Neve, Sinet, Molle \& Nicole, 1983) aiming to define the relationships between these three microelements and both enzymes, zinc plasma levels were found to be normal in people with Down syndrome. Subsequently, Annerén reported, through microprobe nuclear analysis and atomic absorption spectrometry, that zinc levels in the erythrocytes (Annerén, Johansson \& Lindh, 1985) and serum (Annerén \& Gebre-Medhin, 1987) were significantly reduced in people with Down syndrome compared with a control group. The relationship between circulating thymic hormone (FTS) and zinc has been studied by Fabris et al. (1984). These authors, starting from the baseline of the decreased concentration of FTS and the presence of factors inhibiting the biological activity of FTS in vitro in the plasma of normal individuals aged over 50 years and in the majority of young people with Down syndrome, reported that the use of zinc sulphate in people with Down syndrome produces hormone levels of FTS and fully prevents FTS-inhibiting activity. Such results suggest that the biologically active FTS is the component bound with zinc and that the increasing FTS activity in the elderly and in people with Down syndrome could be the result of modifications in the pathway of zinc-dependent activation of FTS, probably associated with zinc-deficiency. Subsequently, Fabris, Mocchegiani, Muzzioli and Provinciali $(1988,1991)$ suggested that there were correlations between the thymus, zinc and neuroendocrine system. Franceschi et al. (1988) gave $\mathrm{lmg} / \mathrm{kg} /$ day of $\mathrm{Zn++}$ as zinc sulphate, in two trials of 2 months with a gap of 10 months, to 18 children with Down syndrome and a clinical history of respiratory, ear and skin infections, low plasma levels of FTS, high plasma levels of unbound molecules of FTS and a decreased absolute number of circulating $\mathrm{T}$ lymphocytes. After each trial a dramatic increase of plasma levels of FTS, a near complete disappearance of the inactive molecules of FTS, and a significant increase of the absolute number of circulating $\mathrm{T}$ lymphocytes occurred, the zinc levels were corrected, the infections decreased and school attendance increased. The decreased number of circulating B lymphocytes and the impaired lymphocyte response to concanavalin A and phytohemagglutinin were not modified. These positive effects were present also in those children with Down syndrome without apparent zinc deficiency. These results were not confirmed by Lockitch et al. (1989), who administered zinc gluconate or placebo alternately for periods of 6 months to a group of 64 children with Down syndrome and obtained an increase up to $150 \%$ of the mean concentrations of zinc in the first group, a tendency towards a decrease of days or episodes of cough and fever, but without any effect on other clinical items, or on copper, immunoglobulins and complement serum levels, on the number of lymphocytes, nor on the in vitro response to mitogens. Napolitano, Palka, Grimaldi, et al. (1990) used a therapeutic trial with $\mathrm{lmg} / \mathrm{kg} /$ day of zinc sulphate on 22 people with Down syndrome for times ranging from 6 to 9 months. Fifteen out of 22 people reached a higher centile on their growth charts. The mean rate of height growth increased from $23.84 \mathrm{~mm} / 6$ months to $40.807 .68 \mathrm{~mm} / 6$ months. Growth hormone (GH) and serum somatomedins increased. Napolitano, Palka, Lio, et al. (1990) showed a decrease of free T3 in 17 people with Down syndrome and subclinical hypothyroidism treated with zinc sulphate, and found 9 people with Down syndrome and low zinc levels whose thyroid function improved with zinc supplementation. Stabile et al. (1991) used zinc sulphate at a dosage of $20 \mathrm{mg} / \mathrm{kg} /$ day for 2 months in 38 home-reared children with Down syndrome, 24 of whom had low zinc levels and 14 normal zinc levels. No correlation was found between low zinc levels and the recurrence and/or the intensity of infections. Participants with low zinc levels showed a decreased response to the phytohemagglutinin of peripheral mononuclear blood cells compared with those with normal zinc levels. A significant increase in the synthesis of DNA was obtained after the administration of zinc sulphate orally. Indeed, the lymphocyte response to phytohemagglutinin was normal in all participants up to 6 months since the end of treatment with zinc and decreased in half of the participants 22 months after the end of the treatment. Licastro et al. (1992) reported that 25 children with Down syndrome and low zinc blood levels, high TSH levels and low levels of rT3, reached, after 4 months of treatment with zinc sulphate, normalisation of zinc levels, thymulin, TSH and a significant increase of plasma levels of rT3. After treatment with zinc no difference was found between children with Down syndrome and the 14 control children. Supplementation with zinc was also associated with a decreased incidence of infectious diseases and an increase in school attendance. Licastro, Mocchegiani, Masi and Fabris (1993) and Licastro et al. (1994) subsequently confirmed such data. It has been shown that zinc supplementation enables DNA repair in lymphocytes of people with Down syndrome (Chiricolo, Musa, Monti, Zannotti \& Franceschi, 1993). Recently, Bucci et al. (1999) examined a group of individuals with Down syndrome who had a reverse correlation between plasma levels of zinc and TSH levels. The TSH high levels of people with low zinc levels were normalised, after six months of zinc sulphate supplementation. Such discordant results in the literature induced us to carry out a project which compared zinc levels with some clinical and biochemical values during a follow-up study of people with Down syndrome in our Institute.

\section{Materials and Methods}

A sample of 120 people with Down syndrome (mean age 13 years, age range $0.4-48.1$ years) were submitted to colorimetric assay of zinc levels. Ninety-six $(80 \%)$ of them showed levels within the normal range, whereas the remaining $24(20 \%)$ had levels below the normal range. Both groups were compared with regard to the following items: growth hormone secretion, $\operatorname{IgA}$ and $\operatorname{IgG}$ antigliadin antibodies, presence of coeliac disease, T3, T4, fT3, fT4, $\mathrm{TSH}$, hypothyroidism, hyperthyroidism, CD4/CD8 ratio, total immunoglobulins $\mathrm{G}$ and subclasses. Each sample distribution was tested for normality, using three tests (Kolgomorov-Smirnov and Lilliefors tests for normality, Shapiro-Wilk's W test). Where normal distributions were 
found Student's t test was used, while Wald-Wolfowitz Runs test, Mann-Whitney U test and Kolmogorov-Smirnov test were used when parametric assumptions were not met.

\section{Results}

No significant differences were found between the two groups with regard to growth hormone secretion, IgA and IgG antigliadin antibodies, coeliac disease, thyroid dysfunction, T3, T4, fT3, fT4, and TSH values, CD4/CD8 ratio and total IgG. The subclass IgG4 was significantly lower in the group of participants with normal zinc levels. The distribution in this case differed significantly from normality (Kolgomorov-Smirnov one-sample test: $D=.19615$, $p<.01$; Lilliefors test: $p<.01$; Shapiro-Wilk's $W$ test: $W$ $=0.75116, p<.0001)$, therefore non parametric tests were conducted. The Wald-Wolfowitz Runs test $(Z=-2.52320 ; p$ $<.02)$, the Mann-Whitney U test $(U=370.5 ; Z=-2.08633$; $p<.05)$ and the Kolgomorov-Smirnov two-sample test $(p<$ $.05)$ all indicated a significant difference between the two groups.

\section{Conclusion}

Our results do not identify any statistically significant difference between low zinc levels and normal zinc levels with regard to the evaluated items. The state of zinc deficiency, in the sample of people with Down syndrome examined, does not appear to be associated with any dysfunction in growth hormone secretion, proneness to coeliac disease, thyroid function or immune function.

\section{Correspondence}

Dr. Corrado Romano - Unità Operativa Autonoma di Pediatria, Oasi Institute (IRCCS), Via Conte Ruggero, 73, 94018 Troina (EN), Italy. P Phone: +39-0935-936III • Fax: +39-0935-653327•E-mail: cromano@oasi.en.it

\section{References}

Aggett, R.J. (1989) Severe zinc deficiency. In C.R. Mills (Ed.) Zinc in Human Biology (pp 259-279). New York: Springer-Verlag.

Allen, J.I., Perri, R.T., McClain, C.J., \& Kay, N.E. (1983) Alterations in human natural killer cell activity and monocyte cytotoxicity induced by zinc deficiency. Journal of Laboratory and Clinical Medicine, 102, 577-589.

Annerèn, G., Johansson, E. \& Lindh, U. (1985) Trace element profiles in individual blood cells from patients with Down's syndrome. Acta Paediatrica Scandinavica, 74, 259-263.

Annerèn, G. \& Gebre-Medhin, M. (1987) Trace elements and transport proteins in serum of children with Down syndrome and of healthy siblings living in the same environment. Human Nutrition. Clinical Nutrition, 41, 291-299.

Bjorksten, B., Back, O., Gustavson, K.H., Hallmans, G., Hagglof, B. \& Tarnvik, A. (1980) Zinc and immune function in Down's syndrome. Acta Paediatrica Scandinavica, 69, 183-187.
Briggs, W.A., Pedersen, M., Mahajan, S., Sillix, D.H., Prasad, A.S. \& McDonald, F.D. (1982) Lymphocyte and granulocyte function in zinc treated and zinc deficient hemodialysis. Kidney International, 21, 827-832.

Bucci, I., Napolitano, G., Giuliani, C., Lio, S., Minnucci, A., Di Giacomo, F., Calabrese, G., Sabatino, G., Palka, G. \& Monaco, F. (1999) Zinc sulphate supplementation improves thyroid function in hypozincemic Down children. Biological Trace Element Research, 67, 257-268.

Chiricolo, M., Musa, A.R., Monti, D., Zannotti, M. \& Franceschi, C. (1993) Enhanced DNA repair in lymphocytes of Down syndrome patients: the influence of zinc nutritional supplementation. Mutation Research, 295, 105-111.

Clegg, M.S., Keen, C.L. \& Hurley, L.S. (1989) Biochemical pathologies of zinc deficiency in C.R. Mills (Ed.) Zinc in Human Biology (pp. 129-145). New York: SpringerVerlag.

Fabris, N., Mocchegiani, E., Amadio, L., Zannotti, M., Licastro, F. \& Franceschi, C. (1984) Thymic hormone deficiency in normal ageing and Down's syndrome: is there a primary failure of the thymus? Lancet, $1(8384)$, 983-986.

Fabris, N., Mocchegiani, E., Muzzioli, M. \& Provinciali, M. (1988) Neuroendocrine-thymus interactions: perspectives for intervention in aging. Annals of the New York Academy of Sciences, 521, 72-87.

Fabris, N., Mocchegiani, E., Muzzioli, M. \& Provinciali, M. (1991) The role of zinc in neuroendocrine-immune interactions during aging. Annals of the New York Academy of Sciences, 621, 314-326.

Franceschi, C., Chiricolo, M., Licastro, F., Zannotti, M., Masi, M., Mocchegiani, E. \& Fabris, N. (1988) Oral zinc supplementation in Down's syndrome: restoration of thymic endocrine activity and of some immune defects. Journal of Mental Deficiency Research, 32, 169-181.

Georges, J.P. (1963). Microcristalline rose oxide of zinc. Semaine Therapentique, 39, 345-346.

Hambidge, K.M., Walravens, P.A. \& Neldner, K.H. (1977) The role of zinc in the pathogenesis and treatment of acrodermatitis enteropathica. In G.J. Brewer \& A.S. Prasad (Eds.), Zinc Metabolism: Current Aspects in Health and Disease (pp. 329-340). New York: Alan R Liss.

Kay, R.G. \& Tasman-Jones, C. (1975) Acute zinc deficiency in man during intravenous alimentation. Australian and New Zealand Journal of Surgery, 45, 325-330.

Jepsen, H.H., Teisner, B. \& Svehag, S.E. (1990) Zinc ions inhibit factor I-mediated release of CRl-bound immune complexes and degradation of cell-bound complement factors C3b and C4b. Scandinavian Journal of Immunology, 31, 397-403.

Licastro, F., Moccheggiani, E., Zannotti, M., Arena, G., Masi, M. \& Fabris, N. (1992) Zinc affects the metabolism of thyroid hormones in children with Down's syndrome: Normalization of thyroid stimulating hormone and of reversal triiodothyronine plasmic levels by dietary zinc supplementation. International Journal of Neuroscience, 65, 259-268.

Licastro, F., Mocchegiani, E., Masi, M. \& Fabris, N. (1993) Modulation of the neuroendocrine system and immune functions by zinc supplementation in children with 
Down's syndrome. Journal of Trace Elements and Electrolytes in Health and Disease, 7, 237-239.

Licastro, F., Chiricolo, M., Mocchegiani, E., Fabris, N., Zannotti, M., Beltrandi, E., Mancini, R., Parente, R., Arena, G. \& Masi, M. (1994) Oral zinc supplementation in Down's syndrome subjects decreased infections and normalized some humoral and cellular immune parameters. Journal of Intellectual Disability Research, 38, 149-162.

Lockitch, G., Puterman, M., Godolphin, W., Sheps, S., Tingle, A.J. \& Quigley, G. (1989) Infection and immunity in Down syndrome: a trial of long-term low oral doses of zinc. Journal of Pediatrics, 114, 781-787.

Napolitano, G., Palka, G., Grimaldi, S., Giuliani, C., Laglia, G., Calabrese, G., Satta, M.A., Neri, G. \& Monaco, F. (1990) Growth delay in Down syndrome and zinc sulphate supplementation. American Journal of Medical Genetics, Suppl 7, 63-65.

Napolitano, G., Palka, G., Lio, S., Bucci, I., De Remigis, P., Stuppia, L. \& Monaco, F. (1990) Is zinc deficiency a cause of subclinical hypothyroidism in Down syndrome ? Annales de Genetique, 33, 9-15.

Neve, J., Sinet, P.M., Molle, L. \& Nicole A. (1983) Selenium, zinc and copper in Down's syndrome (trisomy 21): Blood levels and relations with glutathione peroxidase and superoxide dismutase. Clinica Chimica Acta, 133, 209-214.

Prasad, A.S. (1991) Discovery of human zinc deficiency and studies in an experimental human model. American Journal of Clinical Nutrition, 53, 403-412.

Salas, M. \& Kirchner, H. (1987) Induction of interferon gamma in human leukocyte cultures stimulated by Zn2+. Clinical Immunology and Immunopathology, 45, 139-142.

Singh, A., Failla, M.L. \& Deuster, R.A. (1994) Exercise-induced changes in immune function: effects of zinc supplementation. Journal of Applied Physiology, 76, 2298-2303.

Solomons, N.W. (1988) Zinc and copper. In M.E. Shils \& V.R. Young (Eds.), Modern Nutrition in Health and Disease (7th ed., pp. 238-262). Philadelphia: Lea and Febiger

Stabile, A., Pesaresi, M.A., Stabile, A.M., Pastore, M., Sopo, S.M., Ricci, R., Celestini, E. \& Segni, G. (1991) Immunodeficiency and plasma zinc levels in children with Down's syndrome: A long-term follow-up of oral zinc supplementation. Clinical Immunology and Immunopathology, 58, 207-216.

Todd, W.R., Elvejheim, C.A. \& Hart, E.B. (1934) Zinc in the nutrition of the rat. American Journal of Physiology, 107, 146-156.

Tukiainen, E., Tuomisto, J., Westermarck, T. \& Kupiainen, H. (1980) Nature of lowered 5-hydroxytryptamine uptake by blood platelets of patients with Down's syndrome. Acta Pharmacologica Toxicologica (Copenh), 47, 365-370.

Walsh, C.T., Sandstead, H.H., Prasad, A.S., Newberne, P.M. \& Fraker, P.J. (1994) Zinc health effects and research priorities for the 1990's. Environmental Health Perspectives, 102, 5-46.

Weston, W.L., Huff, J.C., Humbert, J.R., Hambridge, K.N., Neldner, K.H. \& Walravens, P.A. (1977) Zinc correction of defective chemotaxis in acrodermatitis enteropathica. Archives of Dermatology, 13, 422-425.

Zalewski, P.D. (1996) Zinc and immunity: implications for growth, survival and function of lymphoid cells. Journal of Nutrition and Immunology, 4, 39-80. 